\title{
IMAGEN COMO TEXTO, TEXTO COMO IMAGEN*
}

\author{
Elisa RuIz García \\ Universidad Complutense de Madrid \\ zahara@ghis.ucm.es
}

In memoriam de Umberto Eco

\begin{abstract}
«The dialectic of word and image seems to be a constant in the fabric of signs that a culture weaves around itself. [...]. The history of culture is in part the story of a protracted struggle for dominance between pictorial and linguistic signs $»^{1}$.
\end{abstract}

\section{Claves semánticas}

Mi propósito en la presente ocasión es analizar en diacronía la relación texto / imagen a partir de un fragmento bíblico de ambigua interpretación e icónicamente relevante. Algunos comentaristas medievales de las Sagradas Escrituras opinaban que las obras proféticas reúnen ciertas características peculiares que permiten considerar la existencia de un género literario propio o forma prophetialis. El libro más enigmático dentro de ese ámbito es, sin duda alguna, el Apocalipsis, objeto de numerosas discusiones exegéticas ${ }^{2}$. Por tal razón quizá sea interesante observar la trayectoria y la evolución de un pasaje que ha sido comentado e ilustrado profusamente a lo largo de siglos.

Acceder a un texto medieval requiere tener presente la carga semántica de determinadas palabras que constituyen el entramado cultural de la época.

\footnotetext{
*Este trabajo se inscribe en el Proyecto de Investigación «Sumptibus: Edición, producción y distribución del libro en las Edades Media y Moderna». FFI2014-55524-P. Secretaría de Estado de Investigación, Desarrollo e Innovación.

${ }^{1}$ W. J. T. Mitchell, Iconology: Image, Text, Ideology, Chicago, University of Chicago Press, 1986, p. 43.

${ }^{2}$ La obra se incorporó al canon bíblico en el año 382 durante el pontificado del papa san Dámaso en lo que atañe a la Iglesia occidental. En la oriental el reconocimiento fue mucho más tardío (s. IX).
} 
La primera voz que debe ser precisada es el concepto de autoría prevalente. El término indica la función de causa eficiente y, en el caso que nos ocupa, comprende cuatro niveles jerárquicos: Dios $>$ Cristo $>$ el ángel $>$ Juan:

Revelación de Jesús Mesías. Lo que Dios le encargó mostrar a sus siervos sobre lo que tiene que suceder en breve y Él comunicó enviando su ángel a su siervo Juan (Apoc. I, 1).

El cumplimiento del anuncio divino culmina con la aceptación de Juan, quien describe el hecho portentoso acaecido:

Un domingo me arrebató el Espíritu y oí a mis espaldas una voz vibrante como una trompeta que decía: «Lo que vas a ver, escríbelo en un libro» (Apoc. I, 9-11).

Resulta evidente que el discípulo recibió el encargo de transmitir por escrito lo que a continuación iba a ver en clave profética. Conviene recordar a este respecto los tres tipos de visiones reconocidos en ese período:

- Visión corporal: aquella que es realizada con nuestros propios ojos.

- Visión figurada: aquella que, durante un estado de sueño o vigilia, versa sobre cosas que tienen un sentido ${ }^{3}$.

- Visión intelectual: aquella que permite a nuestra mente captar el significado último del mensaje recibido mediante revelación del Espíritu Santo.

Ni que decir tiene que esta última modalidad es la que acontece a Juan.

La dicotomía texto / imagen también merece alguna puntualización semántica. El primer elemento (textus = 'tejido') es una metáfora apenas esbozada en la literatura griega y tradicionalmente atribuida a Quintiliano ${ }^{4}$. El autor latino quizá se refería a la organización compleja del discurso con independencia del medio de comunicación utilizado (oral o escrito). Con el tiempo el sentido de esta figura retórica bidimensional en origen ${ }^{5} \mathrm{y}$, por tanto icónica, terminó por identificarse con el producto derivado de una técnica manual, esto es, un mensaje fijado mediante una escritura alfabética, la cual es lineal y unidireccional ${ }^{6}$, si bien el resultado de la operación gráfica es perceptible

\footnotetext{
${ }^{3}$ Es decir, la imagen simbólica a partir de la que se desarrolla una representación mental.

${ }^{4}$ «Quod si numeris ac modis inest quaedam tacita vis, in oratione ea vehementissima, quantumque interest sensus idem quibus verbis efferatur, tantum verba eadem qua compositione vel in textu iungantur vel in fine claudantur» (Institutio oratoria, IX, 4, 13).

${ }^{5}$ Dante menciona la trama y la urdimbre (Paraiso, vv. 100-102).

${ }^{6}$ Véase Raul Mordenti, L'altra critica. La nuova critica della letteratura tra studi culturali, didattica e informatica, Roma, Meltemi Editore, 2007, cap. 4.
} 
como una magnitud que se expresa en longitud y anchura. En la Edad Media el término «texto» se refería al contenido de una obra base ${ }^{7}$ por oposición a los comentarios o glosas que aquella pudiese generar ${ }^{8}$. En cuanto a la voz «imagen» también conviene evocar el valor que esta palabra encerraba en su momento. El sustantivo se identificaba con la idea de similitudo ${ }^{9}$-esto es, 'semejanza' - y de species $^{10}$ o forma visible que refleja especularmente otra realidad. Esta segunda acepción nos conecta con la visión simbólica que estructura y explica la razón de ser del mundo a los ojos del hombre medieval, que no es otra que alcanzar la trascendencia ${ }^{11}$.

Con el refuerzo de estas puntualizaciones semánticas, resulta más accesible analizar la relación existente entre el texto y la imagen en el pasaje propuesto. Ciertamente, la idea de ver constituye un leitmotiv del Apocalipsis, de ahí la vinculación primigenia entre ambos sistemas de comunicación en el proceso de transmisión de esta obra.

Sin duda alguna, la imagen facilita el paso de la abstracción de los signos escritos a otro nivel de interpretación. La percepción óptica simplifica el proceso de comprensión en el plano intelectual. La contemplación de la ilustración permite que la mente capte directamente y sin otras trabas el significado del mensaje. En realidad, la representación visual no debe ser considerada como un sustituto del texto, sino como un código semántico metadiscursivo para el lector. Como afirmaba Johannes de Salisbury (s. xII), es la imagen -y no el texto- la que ayuda a la comprensión de las cosas invisibles ${ }^{12}$.

La propia naturaleza enigmática del Apocalipsis originó desde fechas tempranas la elaboración de comentarios interpretativos del contenido, tales como los de Ticonio (s. IV), Apringio (s. VI) ${ }^{13}$, Beato de Liébana (s. VIII) o Berengaudus (s. XII), entre otros. Tales escritos complementarios constituyeron una especie de puente entre el lector y el texto por antonomasia. Esta glosa permitía comprender lo que hay de oculto en esas palabras y además añadía

${ }^{7}$ Por antonomasia, los textos bíblicos.

${ }^{8}$ Esta distinción se observa en los testimonios estudiados.

${ }^{9}$ La raíz *im- significa la noción de 'imitar'. La definición de santo Tomás es muy clara: «Ergo dicendum [est ]quod imago proprie dicitur quod procedit ad similitudinem alterius» (Summa Theologica., Prima pars, q. 35, art. 1-2).

${ }^{10} \mathrm{La}$ raíz *spec- se encuentra en el sustantivo speculum ('espejo'), palabra clave en el marco de la axiología medieval. «Hoc enim modo imago dicitur esse species alicuius» (Santo Tomás, Summa Theologica., Prima pars, q. 35, art. 1-2).

${ }^{11}$ San Pablo expresa esa idea de manera certera: «Videmus nunc per speculum in aenigmate» (Ep.ad Cor. I, 13, 12). Nada más lejos de la noción de 'pintar'.

${ }^{12}$ Metalogicon, 1, 24.

${ }^{13}$ San Isidoro elogió la producción de este autor: «Apringio, obispo de la iglesia pacense de las Hispanias, orador elocuente y sabio erudito, interpretó el Apocalipsis del apóstol Juan con sentido sutil y brillante pluma, mejor casi que los antiguos autores eclesiásticos» (De uiris illustribus, cap. 17). 
significados que no estaban expresados en el mensaje original. La exégesis escrituraria establecía una clara distinción entre el sentido literal que reflejaba la intención del autor humano, a la sazón Juan, y el sentido alegórico que otorga un significado auténtico a las cosas que proceden de Dios, fuente de la auctoritas. Este doble registro se basaba en el principio del arquetipo divino. Las ideas que el hombre concibe o realiza no son más que un reflejo de un modelo ínsito en la mente del Altísimo: «Praeterea cognoscit Deus res, quod in ipso est exemplar omnium rerum» ${ }^{14}$. En consecuencia, el artífice parte siempre de una materia que le precede según lo expresa con claridad san Buenaventura, quien afirma que el hombre «hace nuevas composiciones, pero no crea nuevas cosas $\rangle^{15}$.

\section{Realia}

A la luz de los presupuestos teóricos descritos deben ser interpretados los casos prácticos. La relevancia y la antigüedad de la obra escogida justifican la elección. El pasaje seleccionado como muestra experimental es el capítulo XII del Apocalipsis o Libro de las Revelaciones ${ }^{16}$, el cual reza así:

1 Et signum magnum apparuit in caelo: Mulier amicta sole, et luna sub pedibus eius, et super caput eius corona stellarum duodecim;

2 et in utero habens, et clamat parturiens et cruciatur, ut pariat.

3 Et visum est aliud signum in caelo: et ecce Draco rufus magnus, habens capita septem et cornua decem, et super capita sua septem diademata;

4 et cauda eius trahit tertiam partem stellarum caeli et misit eas in terram. Et Draco stetit ante Mulierem, quae erat paritura, ut, cum peperisset, filium eius devoraret.

5 Et peperit filium, masculum, qui recturus est omnes gentes in virga ferrea; et raptus est filius eius ad Deum et ad thronum eius.

6 Et Mulier fugit in desertum, ubi habet locum paratum a Deo, ut ibi pascant illam diebus mille ducentis sexaginta.

7 Et factum est proelium in caelo, Michael et angeli eius, ut proeliarentur cum Dracone. Et Draco pugnavit et angeli eius,

8 et non valuit, neque locus inventus est eorum amplius in caelo.

${ }^{14}$ Santo Tomás, De veritate, q. 2. art. 12.

${ }^{15}$ Ars facit novas compositiones, licet non facit novas res (Sent. III, 37, 1).

${ }^{16}$ Esta obra fue redactada directamente en lengua griega por su autor. La versión latina respeta fielmente el original, como no podía ser de otra manera en materia bíblica, de ahí que se ofrezca el pasaje bajo este ropaje verbal. 
9 Et proiectus est Draco ille magnus, serpens antiquus, qui vocatur Diabolus et Satanas, qui seducit universum orbem; proiectus est in terram, et angeli eius cum illo proiecti sunt.

10 Et audivi vocem magnam in caelo dicentem: "Nunc facta est salus et virtus et regnum Dei nostril et potestas Christi eius, quia proiectus est accusator fratrum nostrorum, qui accusabat illos ante conspectum Dei nostri die ac nocte. 11 Et ipsi vicerunt illum propter sanguinem Agni et propter verbum testimonii sui; et non dilexerunt animam suam usque ad mortem.

12 Propterea laetamini, caeli et qui habitatis in eis. Vae terrae et mari, quia descendit Diabolus ad vos habens iram magnam, sciens quod modicum tempus habet!'”.

13 Et postquam vidit Draco quod proiectus est in terram, persecutus est Mulierem, quae peperit masculum.

14 Et datae sunt Mulieri duae alae aquilae magnae, ut volaret in desertum in locum suum, ubi alitur per tempus et tempora et dimidium temporis a facie serpentis.

15 Et misit Serpens ex ore suo post Mulierem aquam tamquam flumen, ut eam faceret trahi a flumine.

16 Et adiuvit terra Mulierem, et aperuit terra os suum et absorbuit flumen, quod misit Draco de ore suo.

17 Et iratus est Draco in Mulierem et abiit facere proelium cum reliquis de semine eius, qui custodiunt mandata Dei et habent testimonium Iesu

(Apoc. XII, 1-17).

Como se puede apreciar, el texto resulta complejo desde el punto de vista narrativo y de ambigua interpretación ${ }^{17}$. Según se ha visto, los primeros comentarios fueron de fecha temprana, en cambio, son más tardíos los testimonios icónicos conservados. Entre las muestras más antiguas figuran ciertas escenas, utilizadas a modo de portadillas, en Biblias carolingias. Tal sucede con las Sagradas Escrituras depositadas en la basílica de San Pablo Extramuros. El manuscrito contiene una miniatura liminar del Apocalipsis que representa de manera recapitulativa la revelación final ${ }^{18}$. Esta ilustración, al igual que otras versiones originarias de $\operatorname{Tours}^{19}$, desciende de un arquetipo romano del s. vi.

\footnotetext{
${ }^{17}$ Sobre el auténtico sentido de este fragmento hay innumerables hipótesis, tanto desde el punto de vista teológico como artístico. Esta problemática no afecta a nuestro enfoque de la cuestión, centrada en torno a la relación texto / imagen.

${ }^{18}$ Bibbia di San Paolo fuori le Mura (c. 870), ms. s/s, f. 331r. El códice, encargado por el rey Carlos el Calvo, fue ofrecido al papa Juan VIII, con motivo de la coronación del soberano galo. El autor material se llamaba Ingobertus.

${ }^{19}$ Biblia de Grandval (c. 840, Londres, British Library, Add. ms. 10546, f.449r) y Biblia de Vivien (845-846, París, Bibliothèque Nationale de France, ms. Lat. 1, f. 415v).
} 
La constitución de un ciclo completo de imágenes dedicado al texto profético quizá se pueda datar también al final de la Antigüedad tardía, aunque los testimonios conocidos son posteriores. Los ejemplares más fieles respecto de modelos paleocristianos son el Apocalipsis de Tréveris (fig. 1) y otro ejemplar que deriva de esta versión, un manuscrito carolingio elaborado en Francia (fig. 2) $)^{20}$.

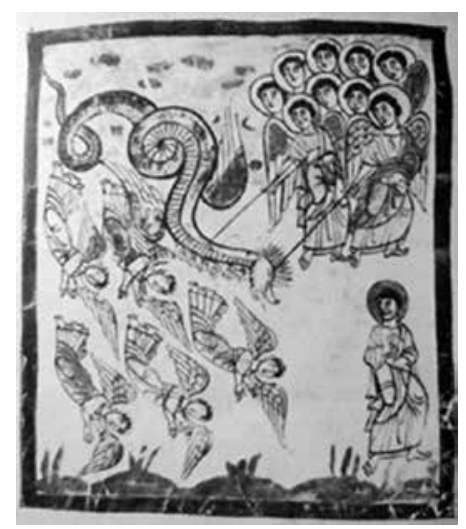

Fig. 1: Expulsión del Dragón y de sus ángeles (Apoc. XII, 7-9), Primer cuarto del s. IX. Tréveris, Staatsbibliothek, Cod. 31, f. 38r.

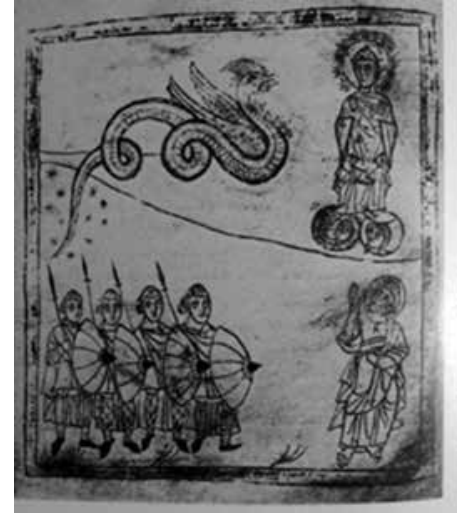

Fig. 2: La Mujer y el Dragón (Apoc. XII, 1-3), segunda mitad del s. Ix. Cambrai (Francia), Bibliothèque Municipale, ms. 386, f. 30r.

Como se puede comprobar, las dos muestras reproducidas se corresponden con sendas escenas del fragmento escogido: la derrota del Dragón y la amenaza del Dragón a la Mujer. Ambas son muy elementales desde el punto de vista artístico e interpretativo del texto.

\section{Ciclo hispano del Apocalipsis}

Por supuesto, las versiones peninsulares elaboradas a partir del Commentarius in Apocalypsin, atribuido a Beato de Liébana, no se pueden comparar con las anteriores. El texto exegético es en realidad una compilación formada por excerpta de diversos autores. Ciertamente, la obra en su conjunto no destaca por su originalidad. Ahora bien, resulta interesante la mise en texte, consistente en una estructura trimembre. El tratamiento del contenido se ajusta a la siguiente ordinatio:

${ }^{20} \mathrm{El}$ ejemplar se data en la segunda mitad del s. Ix. Cambrai (Francia), Bibliothèque Municipale, ms. 386, f. 30r. Hay otros dos manuscritos carolingios (Valenciennes, Bibliothèque Municipale, ms. $99 \mathrm{y} \mathrm{Pa-}$ rís, Bibliothèque Nationale de France, Nouv. Acq. Lat. 1132) que se inspiran en dos versiones intermedias anglosajonas, las cuales quizá estuviesen emparentadas con un ejemplar enviado desde Roma a Inglaterra por el abad Benedictus Biscop, fundador del monasterio de San Pedro de Wearmouth (c. 672). 
- Transcripción de una perícopa bíblica: textus.

- Ilustración que representa el sentido literal de ese texto: historia ${ }^{21}$.

- Comentario que explica el sentido alegórico del mismo: explanatio ${ }^{22}$.

Se ignora el lugar y la fecha aproximada de creación del arquetipo de esta obra. El éxito alcanzado por el Comentario motivó la elaboración de versiones textuales sucesivas ${ }^{23}$, lo cual complica aún más si cabe la filiación de los ejemplares conocidos. Distintos especialistas han diseñado unos stemmata o esquemas arboriformes de distribución de los manuscritos conservados. A nuestro juicio, la propuesta de Peter Klein es la más convincente, aunque discrepamos en algunos $\operatorname{casos}^{24}$.

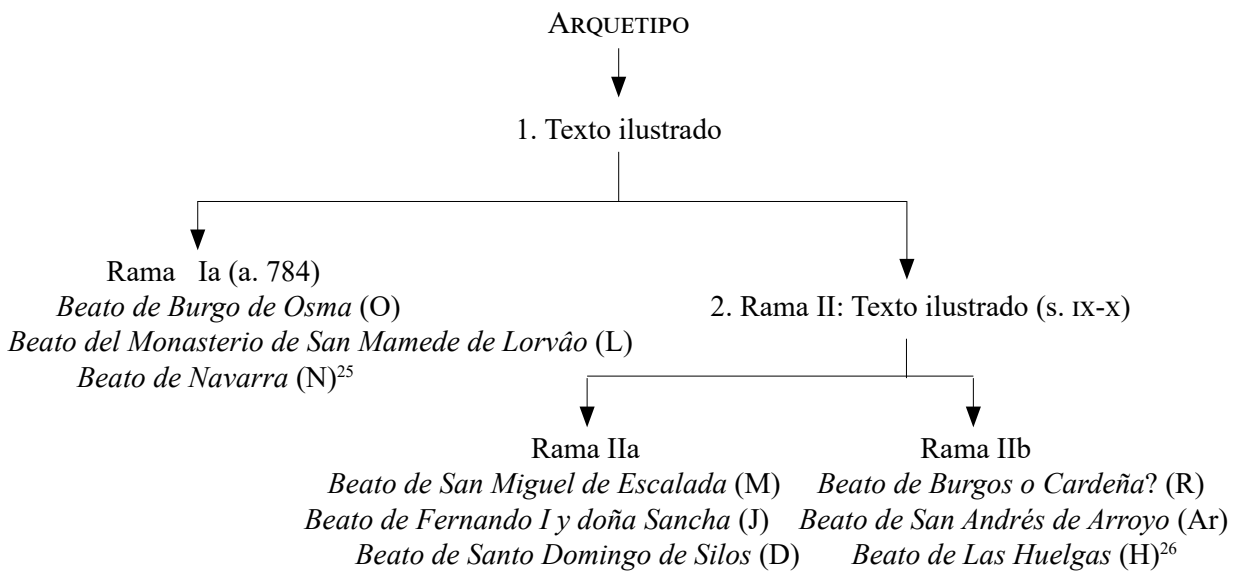

Conviene precisar que, por razones varias, no todos los Beatos contienen la ilustración en cuestión seleccionada. En realidad, hay 17 manuscritos que sí la ofrecen. En el siguiente cuadro sinóptico se han registrado, a título indicativo, los nueve casos más significativos:

\footnotetext{
${ }^{21}$ Esta palabra ([hi] storia tiene un significado exclusivamente icónico.

${ }^{22}$ Este término señala la oposición entre el texto bíblico invariable y la interpretación recopilada por Beato.

${ }^{23}$ Probablemente unas fueron elaboradas en vida del autor y otras son posteriores.

${ }^{24}$ Peter Klein, «Les cycles de l'Apocalypse du Haut Moyen Âge (IX ${ }^{\mathrm{e}}-\mathrm{XII}^{\mathrm{e}} \mathrm{s}$.)», en L'Apocalypse de Jean. Traditions exégétiques et iconographiques, III $-X I{ }^{e}$ siècles. Actes du colloque de la Fondation Hardt, Genève, Droz, 1979, pp. 135-159. Este asunto es tratado también en otras obras suyas. En el stemma tan solo se han reproducido los datos de los mss. aquí estudiados.

${ }^{25}$ Esta ilustración no se corresponde con las que figuran en los otros dos ejemplares de la Rama Ia.

${ }^{26}$ Este ejemplar debería formar parte de la Rama Ia en función del contenido de su ilustración.
} 
Elisa RuIz García

Historia Draconis et Mulieris

\begin{tabular}{|c|c|c|c|c|c|}
\hline Nombre & P. Klein & Fecha & Artifices & Datos bibliográficos & Tituli \\
\hline B. Burgo de Osma (O) & Rama Ia & 1086 & $\begin{array}{l}\text { Petrus } \\
\text { Martinus }\end{array}$ & $\begin{array}{l}\text { Burgo de Osma, B. Cat., } \\
\text { Cod. 1., f. 117v. }\end{array}$ & Sin textos \\
\hline $\begin{array}{l}\text { B. de San Mamede } \\
\text { Lorvâo (L) }\end{array}$ & Rama Ia & 1189 & Egeas & $\begin{array}{c}\text { Lisboa, Torre do } \\
\text { Tombo, s/s, f. } 153 \mathrm{v} .\end{array}$ & Sin textos \\
\hline B. de Navarra (N) & Rama Ia & XII ex. & & $\begin{array}{l}\text { París, BNF, ms. Nov. Acq. } \\
\text { Lat. 1366, ff. 102v-103r. }\end{array}$ & $\begin{array}{l}\text { Tres textos } \\
\text { en el margen }\end{array}$ \\
\hline $\begin{array}{l}\text { B. de San Miguel } \\
\text { de Escalada (M) }\end{array}$ & Rama IIa & $940-945$ & Magius & $\begin{array}{l}\text { Nueva York, Morgan Lib., } \\
\text { M 644, ff. 152v-153r. }\end{array}$ & Textos \\
\hline $\begin{array}{l}\text { B. de Fernando I } \\
\text { y Sancha }(J)\end{array}$ & Rama IIa & 1047 & $\begin{array}{l}\text { Facundus } \\
\text { copista }\end{array}$ & $\begin{array}{l}\text { Madrid, BNE, Vitr. } \\
\text { 14-2, f. 186v-187r. }\end{array}$ & Textos \\
\hline $\begin{array}{l}\text { B. de Santo Domingo } \\
\text { de Silos (D) }\end{array}$ & Rama IIa & $\begin{array}{l}1091- \\
1109\end{array}$ & $\begin{array}{l}\text { Dominicus } \\
\text { Petrus }\end{array}$ & $\begin{array}{l}\text { Londres, BL, Add. ms. } \\
11695 \text {, ff. 147v-148r. }\end{array}$ & Textos \\
\hline $\begin{array}{l}\text { B. de ¿Castilla } \\
\text { Burgos? (R) }\end{array}$ & Rama IIb & c. 1175 & & $\begin{array}{c}\text { Manchester, J. Rylands Univ., } \\
\text { ms. Lat. 8, ff. 142v-143r. }\end{array}$ & Textos \\
\hline B. de Las Huelgas $(\mathrm{H})^{27}$ & Rama IIb & a. 1220 & & $\begin{array}{l}\text { Nueva York, Morgan Lib., } \\
\text { M 429, ff. 101v-102r. }\end{array}$ & Textos \\
\hline $\begin{array}{l}\text { B. de San Andrés } \\
\text { de Arroyo (Ar) }\end{array}$ & Rama IIb & $\begin{array}{c}c .1220- \\
1235\end{array}$ & & $\begin{array}{l}\text { París, BNF, ms. Nov. Acq. } \\
\text { Lat. 2290, ff. 110v-111r. }\end{array}$ & Sin textos \\
\hline
\end{tabular}

El artífice que ideó el modelo icónico supo reflejar la grandiosidad del universo visionario de Juan. La fantasía creativa en materia de imágenes destaca por su originalidad. Esta joya codicológica altomedieval contiene un interesantísimo y amplio programa iconográfico, compuesto por 76 ilustraciones. En el curso de la traditio se completó la edición con un comentario de san Jerónimo al Libro de Daniel. Esta parte también se enriqueció con otras 11 ilustraciones. Como es sabido, se conserva un elevado número de ejemplares que van desde el siglo IX hasta la primera mitad del siglo XIII.

El éxito de la obra supuso lógicamente la necesidad de obtener copias a partir de un modelo del Comentario para atender la demanda de ejemplares. Una vez establecido el arquetipo, fueron surgiendo diferencias significativas durante el proceso de transmisión, a pesar de que los iluminadores procurasen imitar fielmente el antígrafo. Este hecho es un fenómeno habitual en todo proceso de transmisión de imágenes. A menudo las alteraciones originadas en el acto de la copia afectan profundamente a la sustancia de la escena representada. Cuando un rasgo se ha infiltrado y suele aparecer en diversos testes, el estilema se cristaliza y termina por convertirse en una característica iconográfica. La producción libraria de los Beatos se desarrolló durante siglos y en

${ }^{27}$ Se trata de una copia del manuscrito relacionado con el monasterio de San Salvador de Tábara (Zamora), Madrid, Archivo Histórico Nacional, cod. 1097B. Fue comenzado por Magio y terminado por su discípulo Emeterio en el año 970. Este ejemplar fue el modelo de este códice de Las Huelgas. 
diversos emplazamientos geográficos. La pervivencia en el tiempo encierra gran interés porque permite comprobar las modificaciones que los distintos iluminadores han ido introduciendo en sintonía con los estilos artísticos vigentes en cada época y, al tiempo, reconstruir la filiación de los manuscritos.

Con el fin de facilitar el argumentario técnico expuesto a continuación, he traducido el texto latino con omisión de aquellos datos que no han sido tenidos en cuenta por los ilustradores:

Y una gran señal apareció en el cielo: una Mujer adornada con el sol y con la luna debajo de sus pies, y sobre su cabeza una corona de doce estrellas [...]. Y otra señal fue vista [...]: un Dragón grande, rojo, que tenía siete cabezas [...], y con su cola arrastró la tercera parte de las estrellas del cielo y las arrojó a la tierra [...]. Y el Dragón se apostó frente a la Mujer que iba a dar a luz para devorar a su Hijo cuando naciera. Ella dio a luz un Hijo varón destinado a regir todas las gentes [...]. Y le fue arrebatado su Hijo y lo llevaron ante Dios y su trono [...]. La Mujer huyó al desierto, donde tiene un lugar reservado por Dios [...]. Y se trabó una batalla en el cielo: Miguel y sus ángeles iniciaron el combate contra el Dragón [...]. Lucharon el Dragón y sus ángeles [secuaces], pero no vencieron y desaparecieron del cielo definitivamente. Al gran Dragón, a la serpiente primordial, que se llama diablo y Satanás y seduce a la tierra entera, lo precipitaron a la tierra, y precipitaron también a sus ángeles [secuaces] con él [...]. Cuando vio el Dragón que los habían arrojado a la tierra, se puso a perseguir a la Mujer [...]. Le pusieron a la Mujer dos alas de águila real para que volase a su lugar en el desierto, donde sería sustentada un año y otro año y medio lejos de la serpiente. La serpiente, persiguiendo a la Mujer, lanzó por su boca una corriente de agua para que el río la arrastrase, pero la tierra salió en ayuda de la Mujer, abrió su boca y se bebió el río salido de la boca de la serpiente (Apoc. XII, 1-17).

\section{Formas de representar icónicamente los asuntos}

Antes de iniciar un estudio comparativo de los testimonios, conviene fijar algunos principios metodológicos. La finalidad de toda ilustración libraria es explicitar visualmente el contenido del texto. Este objetivo requiere reproducir icónicamente el asunto verbal tratado. En la Edad Media, cuando se trataba de representaciones figurativas o simbólicas, se observaba la aplicación de diversas estrategias narrativas, denominadas «métodos» por diversos especialistas $^{28}$. En principio se distinguen tres modalidades tradicionales:

\footnotetext{
${ }^{28}$ Véase, en particular, Kurtz Weitzmann, Illustrations in Roll and Codex [1947], Princeton, New Jersey, Princeton University Press, 1970. Se recomienda la consulta de la obra en lengua inglesa en lugar de la versión española.
} 
Método simultáneo: dícese de la composición icónica en la que se representan distintas acciones dentro de una misma escena sin respetar la unidad de tiempo. Esta modalidad constituye el procedimiento más utilizado en las etapas iniciales del establecimiento de un asunto ilustrativo (figs. 3-10).

Método monoescénico: dícese de la composición icónica en la que se representa una sola acción en cada escena. El procedimiento se basa en el principio de las tres unidades clásicas (acción, lugar y tiempo). La última coordenada presupone la condensación del factor cronológico en un punto concreto o momento.

Método cíclico: dícese de la composición icónica en la que se representa el contenido de un texto mediante escenas sucesivas. Se basa en el principio de unidad de acción, lugar y tiempo. En este caso el factor tiempo se contempla desde un punto de vista durativo y progresivo.

\section{La relación texto / imagen en los Beatos}

El «logocentrismo», fenómeno propio de la cultura occidental, originó que los textos cobrasen una importancia inusitada en la Edad Media, lo cual propició la aceptación generalizada del principio de inviolabilidad de los mismos. El mensaje transmitido a través de un sistema formalizado de signos lingüísticos era per se inalterable, realidad muy tardíamente expresada con la fórmula ne varietur, mención que explicitaba la prohibición de introducir un cambio en un escrito o en una partitura musical, máxime si la creación en cuestión pertenecía a la esfera de lo sagrado. En cambio, los autores del comentario y del tratamiento del aparato icónico de un ejemplar siempre han gozado de mayor libertad a la hora de expresarse en términos hermenéuticos y artísticos. Este hecho explica que frente a un texto invariable, como lo es el fragmento del Apocalipsis, hayan surgido diferentes interpretaciones.

En el Comentario de Beato la figura de la Mujer personifica a la Iglesia en tanto que institución celestial (representada por las estrellas) y también terrenal (encarnada por la luna). Esta fundación sagrada (Ecclesia) está sometida desde sus orígenes a las fuerzas del Mal que intentan destruirla por todos los medios (Draco, Serpens, Diabolus et Satanas). La lucha será incesante y continuada hasta que se produzca la Segunda Venida de Cristo, hecho que supondrá el fin del mundo y el triunfo definitivo del Bien y de cuantos han perseverado en esa creencia. Este mensaje esperanzador ha sido revelado a Juan en clave profética, de ahí la necesidad de establecer una ecuación entre los significantes (el sentido literal) y los significados (el sentido alegórico). 
La aplicación del método simultáneo a la hora de plasmar la visión de Juan fue todo un acierto. La perspectiva global de un conjunto de episodios variopintos insertos en el marco de una página, sencilla o doble, produce en el espectador la sensación de estar asistiendo a un acontecimiento excepcional. El intenso cromatismo y la ausencia de una consecutio temporum contribuyen a crear un ambiente enigmático y onírico. En todo momento se reclama la sagacidad de la persona que tiene el libro ante su vista para que descodifique el mensaje.

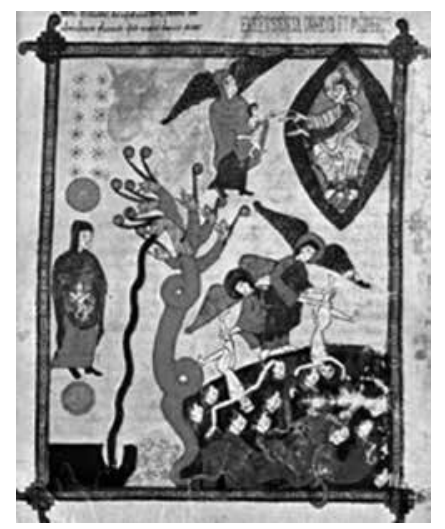

Fig. 3: Beato de Burgo de Osma (O), a. 1086. Burgo de Osma, Biblioteca de la Catedral, Cod. 1, f. 117v.

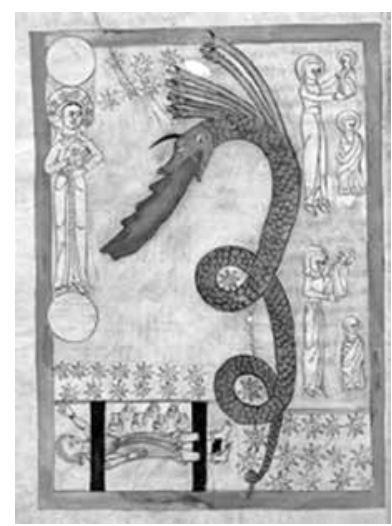

Fig. 4: Beato del Monasterio de San Mamede de Lorvâo (L), a. 1189. Lisboa, A. N. da Torre do Tombo, s/s, f. 153v.

Concebir una ilustración en correspondencia estrecha con el fragmento seleccionado no era una tarea fácil, por ello merece la pena comparar varios testimonios. El análisis de las miniaturas elegidas demuestra que fueron compuestas ocho de ellas según el método simultáneo, en lo que respecta a la forma de presentar el asunto narrado. Se observa con claridad la existencia de unas unidades de acción o «narremas» que han sido objeto de una transposición al lenguaje gráfico. Las dos primeras entradas del cuadro I, datadas en los años 1086 y 1189, reproducen un modelo antiguo, hoy perdido, y caracterizado por una interpretación sintética del fragmento bíblico. Las dificultades intrínsecas del relato han motivado que el artífice primitivo se hubiese limitado a representar algunos asuntos como se puede comprobar leyendo el texto e intentando localizar los episodios tratados (fig. 3). Otro tanto sucede en el siguiente caso: la interpretación del texto es muy torpe. Tan solo se han representado algunos narremas. El tratamiento de la miniatura produce la sensación de que el illuminator que compuso el modelo no había comprendido bien el contenido del relato. La realización artística de la ilustración es 
asimismo mediocre (fig. 4). Ambos manuscritos descienden probablemente de una misma rama y dependen de un modelo común. El proceso de la traditio ha originado probablemente una desfiguración de los asuntos.

Como es sabido, los elementos más estables en las miniaturas son los movimientos y gestos que expresan una determinada acción ${ }^{29}$. Estos llegan a fijarse hasta tal punto que es posible determinar el arquetipo o repertorio al que pertenece una figura a través de las características de su trazado. En los testimonios 5, 6, 7 y 8 el personaje central de la Mujer siempre extiende su brazo izquierdo para señalar con un inequívoco gesto deíctico de la mano la presencia amenazante del Dragón. Este movimiento no se encuentra en los restantes manuscritos estudiados. Las ilustraciones 5, 6 y 7 son muy homogéneas. Se advierte que proceden de un subarquetipo común, caracterizado por interpretar con fidelidad el texto y aportar soluciones novedosas en el plano pictórico. El ejemplar más antiguo conservado se debe a los pinceles de Magius, quien introdujo una superposición de franjas cromáticas horizontales a modo de fondo de las escenas. Este recurso establece de manera icónica una disposición de los narremas que prefigura la técnica del registro ${ }^{30}$ (fig. 5). En el interior de la miniatura se han reproducido algunos textos ${ }^{31}$ que facilitan la comprensión del mensaje visual bajo la forma de tituli o leyendas. Estas secuencias verbales tal vez figurasen en el diseño original en concepto de notas de taller. En cualquier caso su lectura facilita al espectador la interpretación de los episodios. La organización de las acciones representadas refleja con mayor fidelidad el flujo temporal de la narración.

El siguiente testimonio (fig. 6) está emparentado genéticamente con el ejemplar anterior. Presenta las mismas características formales y también ofrece los tituli explicativos. Este manuscrito fue realizado en tiempos de Fernando I y doña Sancha, monarcas que se distinguieron por su patrocinio de la cultura escrita ${ }^{32}$. Otro tanto cabría decir del séptimo componente de esta serie (fig. 7). Fue elaborado en el prestigioso monasterio de Santo Domingo de Silos. El miniaturista sigue el modelo de su antígrafo con meticulosidad, pero a causa de sus dotes artísticas reinterpreta los asuntos y les proporciona

${ }^{29}$ La relación entre los participantes de una escena narrativa también es un criterio que a veces resulta decisivo para encuadrar una imagen dentro de una determinada serie.

${ }^{30}$ Término que designa a un conjunto de elementos colocados sobre una misma línea horizontal (real o imaginaria) en una composición que reúne varias escenas o decoraciones superpuestas.

${ }^{31}$ Los versículos reproducidos ofrecen algunas variantes respecto de la versión Vulgata.

${ }^{32}$ Elisa Ruiz García, «Arma regis: los libros de Fernando I y doña Sancha», en Lemir, 18 (2014), pp. 137-176. [En línea]. Enlace: <http://parnaseo.uv.es/Lemir/Revista/Revista18/05_Ruiz_Elisa.pdf $>$ [Consulta: $28 / 02 / 2016]$. 


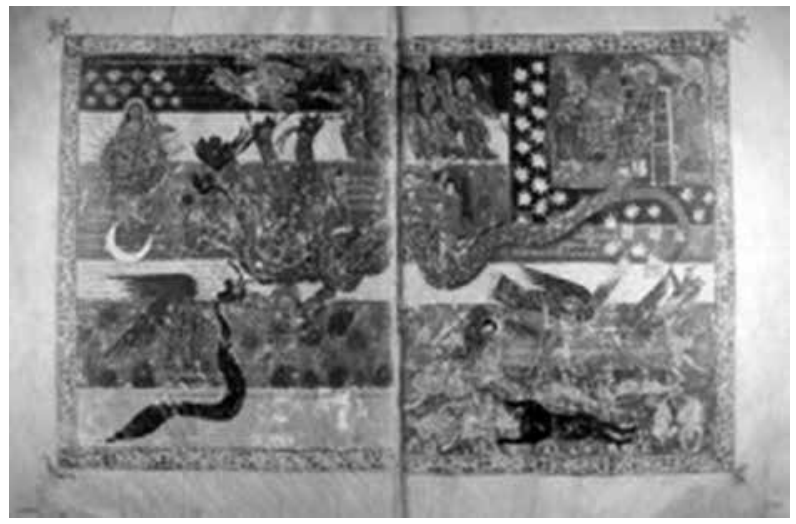

Fig. 5: Beato de San Miguel de Escalada (M), a. 962. Nueva York, Pierpont Morgan Library, M. 644, ff. 152v-153r.
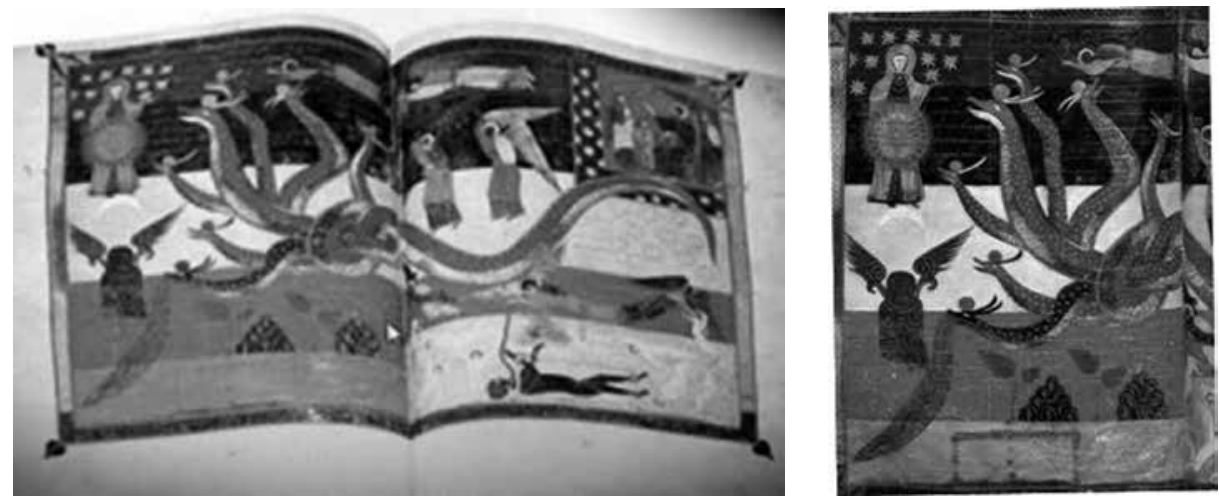

Fig. 6: Beato de Fernando Iy doña Sancha (J). San Isidoro de León, a. 1047. Madrid, Biblioteca Nacional de España, ms. Vitr. 14-2, ff. 186v-187r.

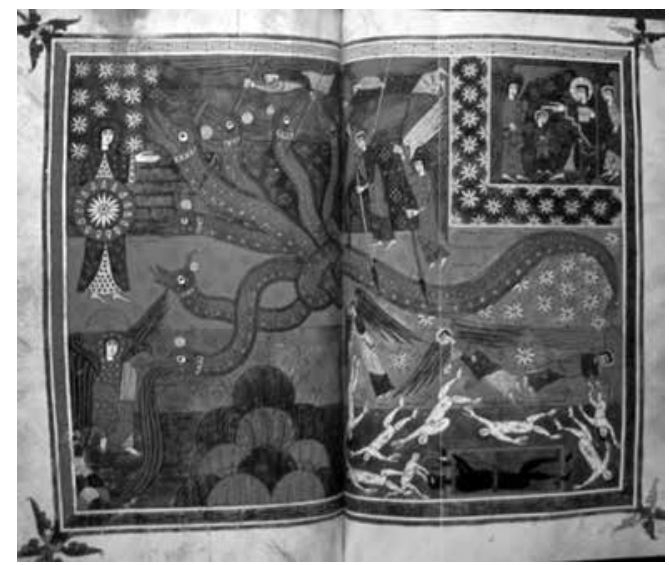

Fig. 7: Beato de Santo Domingo de Silos (D), a. 1091-1109. Londres, British Library, ms. Addit. 11695, ff. 147v-148r. 


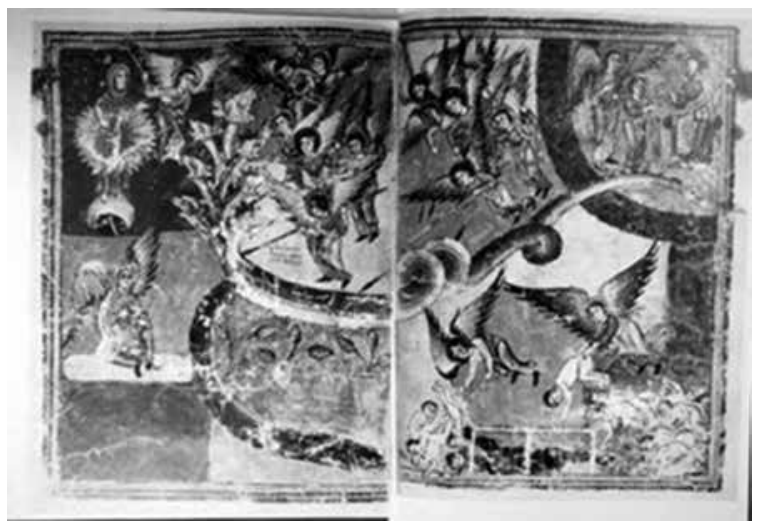

Fig. 8: Beato de Las Huelgas (H), a. 1220.

Nueva York, Pierpont Morgan Library, M. 429, ff. 101v-102r.

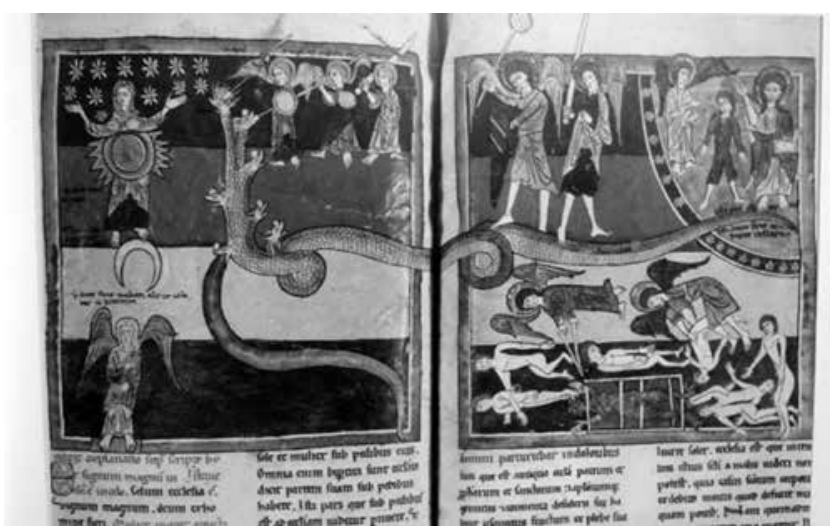

Fig. 9: Beato de Burgos o Cardeña? (R), c. 1175.

Manchester, John Rylands University, ms. Lat. 8, ff. 142v-143r.

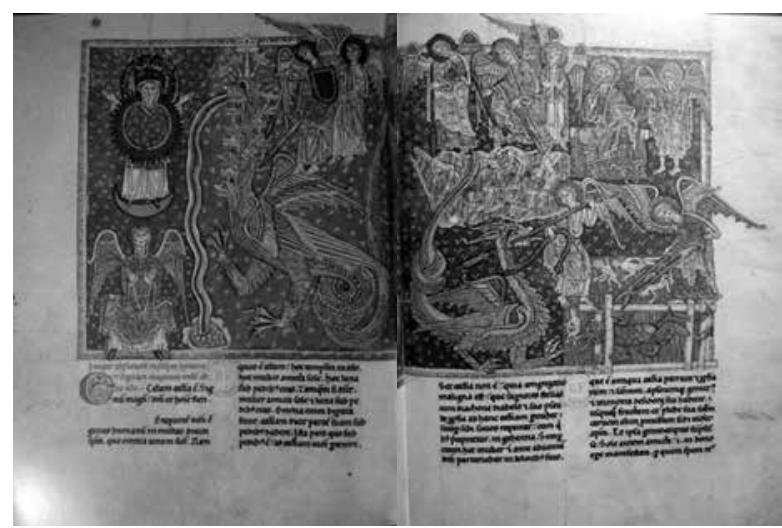

Fig. 10: Beato de San Andrés de Arroyo (Ar), c. 1220-1235.

París, Bibliothèque Nationale de France, ms. Nov. Acq. Lat. 2290, ff. 110v-111r. 
un vigor inusitado gracias al empleo de una rica gama cromática en la que domina un pigmento rojo intenso que atrae las miradas.

El Beato de Las Huelgas, a pesar de haber sido considerado por Klein como un ejemplar que depende de la Rama IIb, comparte con los tres anteriores el mismo gesto de la Mujer (fig. 8). La pieza ofrece un extenso colofón, en el cual se agradece la generosidad de una dama anónima que ha costeado la obra. Tampoco hay indicaciones precisas sobre el lugar de emplazamiento del scriptorium ni los nombres de los artífices. Como el manuscrito se encontraba en el monasterio de Las Huelgas en el siglo XVIII, se conjetura que tal vez fuese confeccionado allí. Este cenobio fue fundado por Alfonso VIII y su esposa, Leonor de Plantagenet. Por estar vinculada la institución a la realeza, se ha postulado que la donante pudiese ser doña Berenguela, viuda de Alfonso IX de León y madre de Fernando III el Santo. Es una copia tardía del llamado Beato de Tábara ${ }^{33}$. La miniatura contiene un único titulus: Ubi dracho traxit tercia pars stellarum («Aquí el Dragón arrastra [con su cola] la tercera parte de las estrellas del cielo»).

Los dos testimonios siguientes dependen de un mismo arquetipo. Como se puede observar, el movimiento deíctico de la mano de la Mujer, registrado en los cuatro casos precedentes, ha sido sustituido en esta serie por un gesto arcaizante ya que se inspira en la actitud corporal propia del orante, esto es, elevar ambos brazos en un sentido impetratorio, postura practicada en los primeros siglos del Cristianismo. En el manuscrito hoy custodiado en Manchester (fig. 9), se han conservado los narremas esenciales, pero su tratamiento artístico es más pobre. En cambio, se ha imitado el procedimiento de franjas polícromas instaurado por el archipictor Magius. El ejemplar presenta algunos tituli, trazados en una escritura protogótica más moderna que el texto base.

El Beato de San Andrés de Arroyo (Burgos) (fig. 10) presenta algunas novedades iconográficas, tales como un nimbo estrellado en torno a la cabeza de la Mujer, un orificio, a modo de estanque, que recoge la corriente de agua que emana de la boca del Dragón, la inclusión de un segundo monstruo en forma de serpiente ${ }^{34}$, la ausencia de las estrellas arrastradas por la cola del Dragón, la carencia de un encuadre que separe el ámbito del Padre Eterno del lugar donde combaten los ángeles que encarnan el Bien y el Mal, la omisión de la figura capital del Hijo de la Mujer, la presencia de un escudo heráldico,

${ }^{33}$ Se trata de un ejemplar relacionado con el monasterio de San Salvador de Tábara (Zamora) como ya se anticipó. El modelo no conserva la miniatura correspondiente a este pasaje.

${ }^{34}$ La duplicación se debe a una interpretación errónea del texto bíblico, en donde aparece tras la palabra Dragón el término serpiente como una aposición explicativa del malvado monstruo. 
etc. Asimismo, el fondo de la miniatura a doble página ofrece sectorialmente un tratamiento bicolor azul claro o rojo ${ }^{35}$. Esta ambivalencia cromática significa por oposición el mundo celestial del Bien frente a las regiones del Mal. A pesar de estas novedades, la figura de la Mujer ha sido representada como orante. El ejemplar carece de leyendas explicativas.

El ejemplar llamado Beato de Navarrra (fig. 11), de oscuro origen, contiene una versión iconográfica muy interesante ${ }^{36}$. Desde el punto de vista técnico se aparta por completo del método simultáneo de narración aplicado en los casos anteriores, en donde las acciones tienen lugar dentro de una misma ilustración sin respetar la unidad de tiempo. En cambio, aquí se ha recurrido a un procedimiento secuencial progresivo, esto es, el asunto ha sido concebido de acuerdo con un método cíclico, que ha sido resuelto plásticamente a través de una disposición en forma de registro.

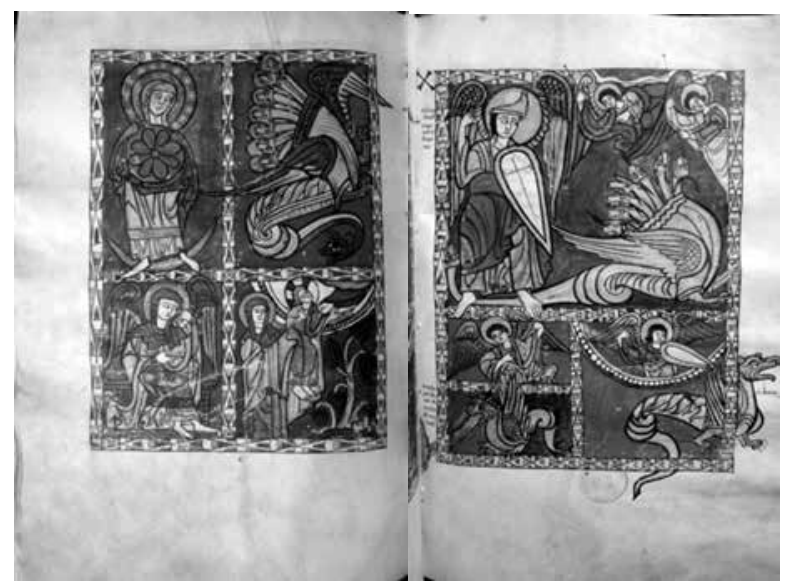

Fig. 11: Beato de Navarra (N), XII ex. París, Bibliothèque Nationale de France, ms. Nouv. Acq. Lat. 1336, ff. 102v-103r.

El argumento es narrado siguiendo un orden cronológico de las acciones. En la primera página se describen los episodios relativos a la Mujer:

- Representación de la Mujer

- Acoso del Dragón

- La Mujer provista de alas se refugia en el desierto, donde da a luz.

- El Hijo es llevado ante el trono del Padre Eterno.

${ }^{35}$ Los paramentos van tachonados con minúsculos triángulos formados por tres puntos o bien por unos asteriscos.

${ }^{36} \mathrm{P}$. Klein, art. cit., incluye este ms. en la Rama Ia. Esta filiación no se compadece con el tratamiento iconográfico. 
En la página afrontada se reproduce la lucha épica entre san Miguel arcángel y el Dragón:

- San Miguel asaetea al Dragón con la ayuda de sus huestes.

- El Dragón es derrotado.

- El Dragón es arrojado fuera del mundo celestial.

En esta versión se ha omitido la representación del inframundo con Satanás encadenado en compañía de sus secuaces. Hay tres tituli colocados en posición marginal en esta página:

- Sanctus Michael pugnat cum Dracone.

- Draco proiecit fluvium de ore suo.

- Ubi Draco proiectus [est] foras.

La presencia de escudos heráldicos confirma la fecha relativamente tardía de este manuscrito amén de otros datos artísticos y paleográficos.

Las diferencias observadas en las 11 ilustraciones estudiadas confirman que la producción de imágenes formó parte de un proceso en continua redefinición, mientras que el texto permaneció invariable. La serie es el resultado de una elaboración hermenéutica que se proyecta en el espacio y en el tiempo.

Una cuestión pendiente sería averiguar quiénes fueron los receptores de estos manuscritos. Los más antiguos se confeccionaron sin duda para atender el servicio monástico. Su carácter escatológico tal vez justificase la presencia en compañía de los libros denominados «espirituales» ${ }^{37}$ por oposición a los litúrgicos en la biblioteca comunitaria. Ahora bien, algunos de los ejemplares más modernos (desde mediados del siglo XI hasta el primer tercio del XIII) quizá fuesen elaborados por encargo de laicos. Por ejemplo, el bellísimo manuscrito de Fernando I y doña Sancha o la pieza conocida bajo el nombre de Beato de Las Huelgas bien podrían haber sido libros cortesanos ${ }^{38}$. En definitiva, el proceso de transmisión del Apocalipsis, como objeto de estudio o lectura por parte de clérigos y laicos, habría contribuido a la progresiva conformación de tres componentes, texto, imagen y comentario por razones hermenéuticas. La articulación de dichos elementos contribuyó a que esta obra se convirtiese en un best seller a lo largo de la historia.

\footnotetext{
${ }^{37} \mathrm{La}$ serie comprendía los textos bíblicos, las Reglas, los Cánones, etc.

${ }^{38}$ Estos ejemplares serían unas muestras tempranas de una bibliofilia laica de carácter devoto. Esta tendencia alcanzará gran auge a partir del período gótico en todo el occidente europeo.
} 


\section{Ciclo anglo-francés del Apocalipsis}

El último libro de la Biblia gozó del favor del público a ambos lados del Canal de la Mancha desde mediados del siglo XIII hasta el final de la etapa gótica. Se conservan 82 manuscritos ilustrados transmisores del Apocalipsis ${ }^{39}$. En este nutrido conjunto de ejemplares se distinguen dos grupos: uno está compuesto por una compilación de excerpta textuales varios; el otro tiene por autor de la parte exegética a Berengaudus, un monje probablemente benedictino, del cual apenas hay noticias biográficas. Esta segunda versión triunfó particularmente en el siglo XIII. La obra de este autor se titula Expositio super septem visiones libri Apocalypsis. En el prólogo explica la razón por la cual Jesucristo nos habla sobre el futuro:

Quia videlicet praesentia visu, praeterita auditu facile cognoscuntur; futura autem, non nisi aut per doctrinam divinarum Scripturarum aut per revelationem agnosci queunt ${ }^{40}$.

El extenso comentario exegético coincide en parte con las interpretaciones de Beato. Literalmente afirma: Haec Mulier Ecclesiam designat ${ }^{41}$. A continuación identifica las 12 estrellas con los apóstoles, el sol con Cristo, los dolores del parto con los sufrimientos de la Iglesia causados por los infieles, etc.

Como en el apartado anterior, la obra consta de tres elementos que forman un todo: un texto base, un comentario y un programa iconográfico. Ahora bien, hay un grupo de manuscritos datados en la etapa anglo-normanda (12501285) que ofrecen una estructura muy peculiar. Son 10 ejemplares misceláneos organizados a causa de su contenido. Por razones de espacio me voy a centrar en un manuscrito concreto ${ }^{42}$, de fecha temprana. Está formado por dos obras independientes en cuanto a su origen, autoría y medio de comunicación empleado ${ }^{43}$, pero perfectamente relacionadas desde el punto de vista temático. Se trata de una Vita Iohannis, en imágenes sin texto alguno, y de una versión del Apocalipsis provista de un comentario transmisor de una glosa latina abreviada en versión francesa y de autoría desconocida ${ }^{44}$. El texto se asemeja al que se encuentra en algunas Biblias moralizadas, aunque con variantes.

\footnotetext{
${ }^{39}$ Suzanne Lewis, Reading images. Narrative discourse and reception in the thirteenth-century illuminated Apocalypse, London, Cambridge University Press, 1995, p. 41.

${ }^{40} P L, 17,843-1058$, col. 843.

${ }^{41} P L, 17$, col. 958.

${ }^{42}$ París, Bibliothèque Nationale de France, ms. Fr. 403.

${ }^{43}$ En un caso el mensaje es exclusivamente icónico, en el otro mixto.

${ }^{44}$ Es decir, que no depende de la glosa de Berengaudus.
} 
La primera parte se inspira probablemente en algunas de las muchas composiciones hagiográficas dedicadas a ensalzar la figura del apóstol y evangelista. El hecho de que esta pieza no ofrezca ninguna secuencia verbalizada indica que la historia legendaria era bien conocida por los potenciales destinatarios, hasta el punto de que la persona poseedora del libro pudiera ser capaz de «leer» las imágenes sin la apoyatura de unas leyendas explicativas. Esta composición icónica del manuscrito anglo-normando, compuesta por catorce ilustraciones, en una disposición a doble registro, constituye un auténtico picture book.

La originalidad de este modelo reside en la manera de fusionar esta parte con la segunda obra. El proyecto expositivo fue concebido desde una perspectiva cronológica. Las primeras ilustraciones relatan algunos hechos de la vida de Juan hasta su detención ordenada por el emperador Domiciano, quien le castiga desterrándole a la isla de Patmos. En ese lugar se desarrolla el hecho portentoso de la visio transmitida por Dios a través del ángel. Es un momento culminante en el ciclo vital del autor que determina una ruptura con el tiempo real. En ese punto se interrumpe la narración biográfica o Vita y se introduce con habilidad el texto del Apocalipsis con su comentario. Entonces el lector penetra en un universo fascinante, mágico y cargado de simbolismo. Cuando el relato de la obra inspirada acaba, se conecta de nuevo con el hilo de la realidad temporal. El emperador Domiciano ha sido asesinado y, en consecuencia, el Senado romano ha revocado todos los decretos del anterior gobernante, incluida la orden de destierro. Juan es de nuevo libre y se dirige a Éfeso para proseguir su predicación. A continuación son representados icónicamente unos hechos legendarios vinculados a este personaje hasta su tránsito inclusive. El procedimiento de narración aplicado resulta sorprendente por su eficacia y modernidad.

\section{Proceso de descontextualización}

Quien organizó la ordinatio de la versión del Apocalipsis, transmitida en el manuscrito 403 de la Bibliothèque Nationale de France, optó por encabezar cada cara del folio con una sola ilustración inspirada en la obra bíblica y colocada en la parte superior de la plana ${ }^{45}$. Debajo se compuso la parte escrita a doble columna: primero el texto bíblico (Tixt) y luego el comentario $(G l o s e)^{46}$. A partir de ese momento los espacios reservados para la escritura

\footnotetext{
${ }^{45}$ Probablemente se podrían localizar otras piezas precursoras de esta disposición.

${ }^{46}$ Este manuscrito está compuesto en francés, lengua cultural hegemónica a ambos lados del canal de la Mancha.
} 
en el interior de los recuadros de las versiones icónicas precedentes resultaron innecesarios, de ahí que las cartelas hayan permanecido en blanco. El manuscrito representa un estadio intermedio entre el libro de imágenes propiamente dicho y el libro ilustrado tradicional. Esta disposición introdujo un cambio sustancial: el método narrativo aplicado no fue el simultáneo, sino el monoescénico. Cada episodio recibía un tratamiento aislado. Por ejemplo, frente a la miniatura a doble página que ilustra la Historia Draconis et Mulieris en el ciclo hispano ${ }^{47}$, se encuentran 6 escenas independientes para representar esos mismos hechos en la versión anglo-normanda (figs. 12 y 13). Esta metodología expositiva desintegradora se cultivó en los sucesivos manuscritos compuestos con posterioridad. Baste con citar el magnífico ejemplar francés, obra de Jean Bapteur y Péronet Lamy (fig. 14).
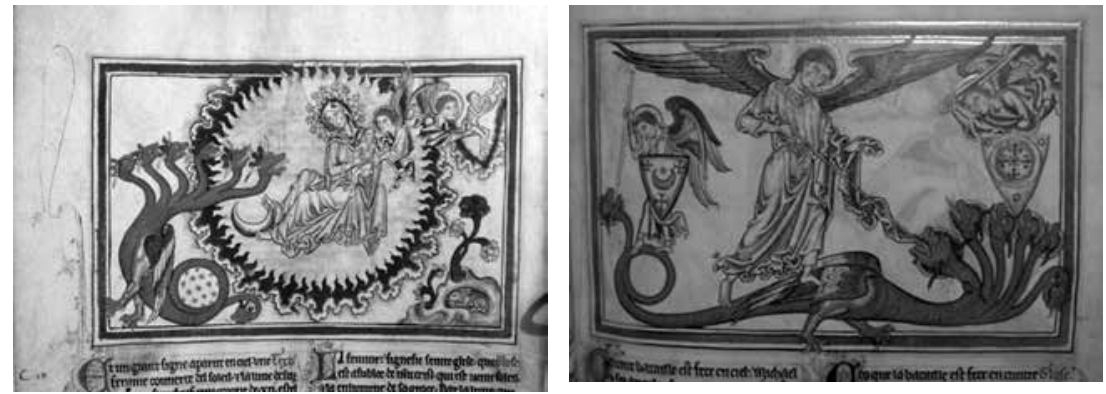

Figs. 12 y 13: Commentarius in Apocalypsin (c. 1250), París, Bibliothèque Nationale de France, ms. Fr. 403, respectivamente, f. 19v y 20r.

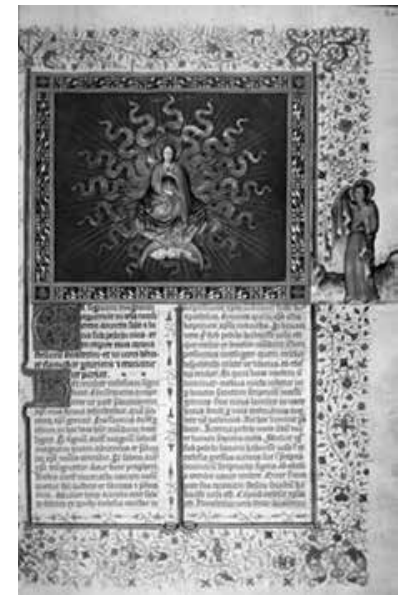

Fig. 14: Apocalipsis figurado de los Duques de Saboya (1428-1435), Madrid, Real Biblioteca del Monasterio de El Escorial, Cod. Vit. 1, f. 20r. Jean Bapteur y Péronet Lamy.

\footnotetext{
${ }^{47}$ La cual representa de manera global y sintética el devenir de la Iglesia y su función escatológica hasta el final de los tiempos.
} 
Los sucesos extraordinarios descritos en el Apocalipsis se prestaban a un cierto paralelismo con las producciones literarias del ciclo artúrico, tan de moda en los medios cortesanos de la sociedad anglo-normanda ${ }^{48}$. Tanto los hechos considerados revelados como los de pura ficción quedaban fuera de la experiencia real de los que accedían a tales textos, bien mediante contemplación de las ilustraciones, bien mediante lectura directa o indirecta ${ }^{49}$. No sabemos en qué grado dichos relatos emocionaban ni tampoco si se les prestaba crédito. Asimismo, ignoramos la clave de interpretación de unas historias fantásticas. Su efecto podría ser múltiple: desde la simple alegoría hasta el anuncio profético de un fin del mundo inminente, pasando por la reflexión moral a título subjetivo o la identificación de los personajes retratados con individuos de carne y hueso. En cualquier caso, conviene recordar que la obra de Juan, tras un despliegue de horror y violencia sin límites, termina de una manera que inspira calma, sosiego y esperanza ya que el texto se cierra con la contemplación mística de Cristo por parte del pretendido autor.

En realidad, el tratamiento individualizado de imágenes dedicadas a glosar un solo episodio facilitó la creación de modelos iconográficos con vida propia ${ }^{50}$. Las figuras de la Mujer apocalíptica y del arcángel san Miguel se convirtieron en unos protagonistas afamados gracias a la difusión de unos prototipos repetidos por doquier sobre distintos soportes y, particularmente, a través de los medios mecánicos. Las ediciones xilográficas ${ }^{51}$ y los grabados desempeñaron un papel determinante en el proceso de cambio de significado (figs. 15 y 16).

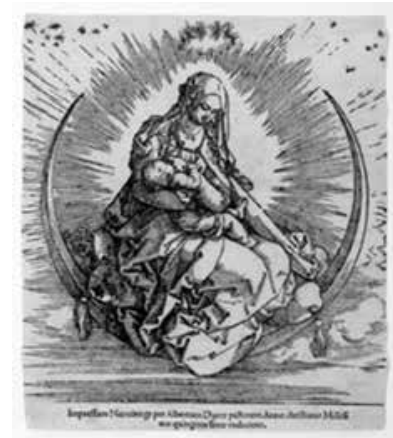

Fig. 15: Alberto Durero, Grabado de la Mujer apocalíptica (1511).

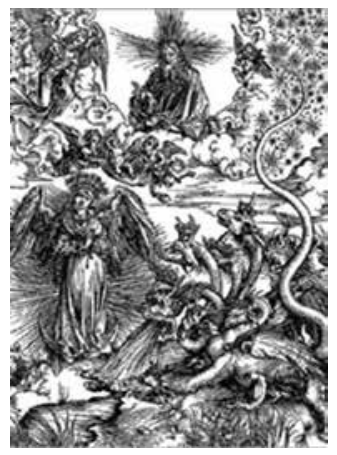

Fig. 16: Alberto Durero, Grabado de la Mujer apocalíptica acosada por el Dragón.

\footnotetext{
${ }^{48}$ En realidad, muchos mss. apocalípticos tuvieron como comitentes a aristócratas laicos.

${ }^{49}$ Es decir, a través de una percepción auditiva.

${ }^{50} \mathrm{Como}$ es natural, todas las implicaciones de estos cambios en lo que respecta a la historia del Arte no se contemplan en este trabajo.

${ }^{51}$ Véase Wilhelm Ludwig Schreiber, Catalogue des livres xylographiques et xylochirographiques [1902], Stuttgart, Anton Hiersemann, 1969.
} 
A la postre actuó un efecto magnético: la Mujer coronada de estrellas, adornada con el Sol y apoyada sobre la Luna fue interpretada como una advocación mariana ${ }^{52}$ cuando se debilitó su relación con el texto sustentante. Otro tanto sucedió con la efigie de san Miguel, el héroe vencedor del Dragón. El arquetipo de este personaje universal subyace en distintas mitologías ya que representa la valentía en estado puro hipostasiada con la defensa de la mujer en peligro. Da igual que la aventura tenga por protagonista a Perseo liberando a Andrómeda, a san Jorge luchando con un dragón o a un galante James Bond defendiendo a una fémina. En los primeros testimonios aquí descritos la imagen equivalía al texto, a partir de la Modernidad el texto depende de la imagen.

Recibido: 29/02/2016

Aceptado: 3/07/2016

${ }^{52} \mathrm{El}$ dogma de la Inmaculada Concepción de la Virgen María fue proclamado el 8 de diciembre de 1854. Esta creencia gozó de particular arraigo en la Península Ibérica desde la Alta Edad Media. 


\section{IMAGEN COMO TEXTO, TEXTO COMO IMAGEN}

RESUMEN: El objetivo de este trabajo es analizar en diacronía la relación texto / imagen a partir de un fragmento bíblico de ambigua interpretación e icónicamente relevante. Se trata del capítulo XII, 1-17 del Apocalipsis. Acceder a un texto medieval requiere tener presente la carga semántica de determinadas palabras que constituyen el entramado cultural de la época. Tras un breve planteamiento de esta cuestión, se pasa revista a los principales testimonios hispanos, anglo-franceses y germánicos. Las diferencias observadas en las ilustraciones estudiadas confirman que la producción de imágenes formó parte de un proceso en continua redefinición. La sustitución del método simultáneo por el monoescénico se tradujo en un cambio de significado. El tratamiento individualizado de imágenes dedicadas a glosar un solo episodio facilitó la creación de modelos iconográficos con vida propia. En los testimonios más antiguos descritos la imagen equivalía al texto, a partir de la Modernidad el texto depende de la imagen.

Palabras Clave: Commentarius in Apocalypsin. Beato de Liébana. Berengaudus. Mujer apocalíptica. Dragón. Métodos de representación icónica.

\section{The Image as TeXt, The TeXt as Image}

ABSTRACT: The aim of this study is to analyze the relationship text-image in diachrony, starting from a biblical piece of ambiguous interpretation and important from the iconic point of view, that is, chapter XII, 1,17 from the Apocalypse. Getting into a medieval text demands having in mind the semantic content of certain words which make up the cultural framework of the time. After a short approach to this question we examine the most important Hispanic, Anglo French and German testimonies. The differences found in the illustrations observed prove that the production of images was part of a process in continuous redefinition. The substitution of the simultaneous method for the monoscenic one resulted in a change of meaning. The individualized treatment of images dedicated to comment an only event made easy the creation of iconografic models with a life of their own. In the oldest examples we have described, the image was equivalent to the text, since Modernity the text depends on the image.

Keywords: Commentarius in Apocalypsin. Beatus of Liébana. Berengaudus. Apocalytic woman. Dragon. Methods of iconic representation. 